\title{
The proof of the vegetable: a commentary on medical futility
}

\author{
Chris Borthwick Victorian Health Promotion Foundation, Australia
}

\begin{abstract}
Patients with 'persistent vegetative state' (PVS) are often cited in the discussions of ethicists as examples of human beings who are unconscious and do not experience life, and a number of theoretical and practical recommendations have been made on that basis. This article examines the evidence and the theoretical rationale for the belief that people with PVS are unconscious and finds them wanting. This conclusion is related to the practice of the discipline of ethics.
\end{abstract}

The bestiaries of mediaeval Europe lived not in a world of visible facts but rather one of symbols. ... The crab, walking sideways, was a symbol of the fraudulent; ... the pelican, which was believed to nourish its young with its own blood, was the analogue of Christ, who feeds mankind with His blood. In such a world there was no thought of hiding behind a clump of reeds actually to observe the habits of a pelican. There would have been no point to it. Once one had grasped the spiritual meaning of the pelican, one lost interest in individual pelicans' (1).

The discipline of medical ethics tends to take the same attitude to its exemplars. A particular condition will generally be described and understood in the manner that produces the clearest ethical conclusion, rather than in a manner that takes account of the inevitable ambiguities of uncertain knowledge and unclassifiable pathology. Ethics has a weakness for limiting cases, and in seeking for them sometimes allows the needs of ethical arguments to dictate the observations on which the arguments are supposedly founded.

One of the leading concerns of modern ethicists has been the distinction between those beings who are accorded the privileges of humanity and those who should be. The identification of a class of people who are 'humans' but not human, if any such could be found, would therefore be central. As McCullagh says: 'Discussions about anencephalics originally concentrated on the manner in which

\section{Key words}

Coma; persistent vegetative state. others should respond to and deal with them. I believe that a substantial part of this discussion was initiated not necessarily because of problems posed by anencephalic infants per se, but because they were seen as examples of a class of subjects who could be separated from the general run of human beings' (2).

Anencephalics have been nominated as one group of candidates for this class. Since at least the case of Karen Ann Quinlan, patients with 'persistent vegetative state' (PVS) have been another. As set out by Mitchell, Kerridge and Lovat in this journal (3), PVS is a condition where patients with head injuries, strokes, medical accidents or cerebral diseases 'are considered to have permanently lost the function of their cerebral cortex. ... All voluntary reactions or behavioural responses reflecting consciousness, volition or emotion at the cerebral cortical level are absent. ... there is no observable experience of pain or suffering. ... They remain permanently unaware...' (4).

The term 'permanent' recurs. It is of particular diagnostic significance, because '.. as yet, no specific laboratory study can confirm the clinical diagnosis of PVS' (5).

That is, it is not possible to predict in advance that any given vegetative state will be persistent, still less permanent. The only means of deciding which initially vegetative patients will qualify for the diagnosis of PVS is to watch them and see if their condition persists.

'Although there is general agreement that there can be no immediate diagnosis of PVS, there is some dispute as to the point at which a confident [emphasis in the original] diagnosis can be made. Many clinicians believe a diagnosis can be made after three months without patient improvement, whereas others, such as the AMA, set a conservative criterion for diagnosis as 12 months of unawareness' (5).

One question that arises is exactly how confident one can be about a diagnosis that can only be established in retrospect. Chronology does not sit easily within pathology. An even more basic point, however, is philosophical. If one were to assume for the sake of argument that all PVS diagnoses in fact remained unfalsified, and that all patients with a diagnosis of PVS continued in that condition till 
their deaths, exactly how, even so, would one go about establishing the reality of their hypothesised unawareness?

One cannot ask them to confirm it, because they cannot speak. One cannot stick a pin into them and see if they jump, because, as Mitchell et al concede, they can and do jump. When Mitchell et al say that there is no observable experience of pain and suffering, they do not mean that there is nothing to observe.

'The PVS patient may "react" to painful stimuli, but he or she does not "feel" pain in the sense of conscious discomfort of the kind that doctors would be obliged to treat or of the type that would or should seriously disturb the family' (5).

\section{'Pain behaviour'}

It is not possible to observe any experience; we can only observe behaviour, and, in general, we act on the assumption that the person is experiencing stimuli similar to those that would have induced us to behave similarly. What evidence can reverse that assumption? How can any person, however clinically expert, conceivably know that a person with PVS feels no pain despite evincing 'pain behaviour'? There is, under the assumption of permanence, no possibility of consulting any people who have been in that situation; if they recover sufficiently to speak they cannot have had the condition, and if they have the condition they will die without speaking. $A$ prior arguments based on neurological theories along the lines of '.. . the brainstem in the PVS condition ... is relatively intact, however, the cerebral hemispheres suffer irreversible damage. ... All voluntary reactions ... reflecting consciousness ... are absent. ... Only a brain with the capacity for consciousness can translate neural activity into an experience' (5) would be convincing only if one believed that we know everything there is to be known about the neurology of consciousness and pain - only if we were certain, for example, that no part of pain is experienced purely through the brainstem. Not only are we not at that stage of knowledge, it is difficult to conjecture how one would go about testing, or even operationalising, the hypothesis. Anencephalic children, similarly, must also have their pain within inverted commas: 'Some anencephalics have grasping, sucking, and vestibular activity and respond to "painful" stimuli. However, the latter is best understood as a reflex pain response mediated by the brainstem' (6).

Here, too, it is difficult to imagine interventions based on such an account of apparent pain reactions getting past an alert human (or, indeed, animal) research ethics committee.

As moral certainty in PVS - indeed, as the very definition of PVS under this presentation - rests heavily on the element of permanence, it is reasonable to ask how reliable this element is in practice, particularly as even Mitchell et al are prepared in a somewhat backhanded way to concede the existence of people diagnosed as having PVS who have recovered.

'Despite the element of uncertainty in the $\stackrel{\overrightarrow{\vec{S}}}{\stackrel{7}{+}}$ diagnostic process, extremely few patients who o remain vegetative after three months ever recover cognitive functions where it is believed that the diagnostic criteria were correctly applied' (5).

When one considers that one is here discussing clients whose appearance of pain is to go untreated, the phrase 'extremely few' has, in the words of Walt Kelly, a disturbing ring of frequency about it. This unease is compounded by consideration of exactly how, when considering pain relief in the ward situation, we are intended to distinguish cases where the diagnostic criteria were correctly applied from those where they were not. As McCullagh comments in relation to the same issue in the area of $\mathrm{or}$ anencephaly: 'This argument, however, necessarily cuts in both directions. If anencephaly was as clearcut a condition as is maintained by those denying these infants the possession of neurological capacities ... then such mistakes would not occur' (7).

Even if we assume that a client in PVS has lost awareness, either PVS is not irreversible or diagnose of PVS are subject to error. In either case, exact how confident can we be that a client hypothetical without awareness will not recover it? Mitchell et $\vec{a}$ t fudge the issue somewhat by sliding from awareness to functional independence.

'They remain permanently unaware, and although half die within 12 months, a quarter may survive for many years. ... In a recent study ... no patient who remained vegetative beyond three months became independent of nursing care' (5).

If we are measuring the recovery of awareness, the number who required nursing care is surely not the index that counts. More relevant, perhaps, is the number who recover awareness. Here Mitchell et al give no figures, but in another study of PVS clients with closed head injury '.. of 84 patients in a vegetative state ... 41 per cent became [sic] conscious by six months, 52 per cent regained consciousness by one year, and 58 per cent $N$ recovered consciousness within the three-year $N$ follow-up interval' (8).

Overall, that is, 49 of 84 patients, or 58 per cent, recovered awareness, and the 'conservative' criterion of a year's silence would have missed five, or six per cent. Where prediction at any point in time is $\stackrel{\mathbb{Q}}{\rightarrow}$ concerned the most important proportion, of course, is not the percentage of the original cohort who recover but the percentage of the survivors at that point in time, and the five late recoveries thus made up an even more significant 12.5 per cent of the 40 clients still comatose after the first year. I have been unable to find any study that involved asking those 
who had emerged from PVS whether they felt pain while in PVS. Mitchell et al go on to state that the obligation to keep a person with PVS alive 'may be overridden, we believe, when we are morally certain that their condition is irreversible. Available clinical evidence would suggest that reasonable moral certainty exists somewhere between three months as a minimum and 12 months...' (9).

This is a usage of the term 'certainty' (or, possibly, a usage of either the term 'moral' or the term 'reasonable') that I have not previously encountered, accepting as it does an error rate of somewhere between 58 per cent of cases as a maximum and six per cent, the last six per cent of recoveries (or, depending on the base population, the last 12.5 per cent) falling into the period beyond twelve months post-trauma where, according to Mitchell et al, '... clinical data indicates [that permanent unconsciousness] is certain' (9).

Mitchell et al use the term 'permanent' some nine times in the article, the term 'irreversible' five times, and the term 'certain' rather too often for comfort.

One must ask, in the light of the evidence, why it is that reasonable, moral, and ethical writers such as Mitchell et al can extract these qualities of permanence and certainty from data that is, to put the matter no more strongly, clearly capable of other interpretations. One hypothesis would be that Mitchell et al structure their interpretation of the recovery (or misdiagnosis) statistics because they require a cleanly differentiated group to constitute a limiting case in a moral argument. In simplifying the issue to the point where a clear moral answer emerges, however, they eliminate the uncertainty that constitutes the source of the primary moral difficulty. Clinical evidence is that the majority of PVS patients are not permanently, irreversibly, or certainly unaware, and any discussion that eliminates by its definitions the possibility that they may recover is doomed to ethical futility.

The case of Karen Ann Quinlan illustrates the range of possible ambiguities. In ethical discussion it is usually taken as axiomatic that Quinlan was not conscious: 'Karen Ann Quinlan ... has not been aware of the extra years of life she has had, and thus has had no benefit from them' (10).

The evidence presented at the hearing cast doubt on this consensus at several points. She was at one time during her PVS observed to be responsive. The judge's statement of the facts of the case notes that '... nurses indicate that [on one occasion] she blinked her eyes two times when asked to and appeared responsive by moving her eyes when talked to but there is no further evidence of this type of reaction thereafter' (11).

As Robinson points out, the criteria for proof of cognition are not fixed. 'What would Karen Quinlan have to do to offer evidence of "cognitive" or "sapient" life? How often would she have to do it? If, as she was reported to have done early in her hospitalisation, she were to blink twice on command, would this earn her a reprieve' (12)?

More evidence might have been discovered if more effort had been taken - Hilary Pole, an English trauma case, had closed eyes, no facial movement, and no bodily movement other than being able to control one toe, which she used to operate a computer-based typing system with which she ran an advocacy organisation for people with disabilities, and I am not myself certain that all clients with PVS are given an examination directed towards communication sufficient to discover all such instances of voluntary control where they exist. Neither faction in the Quinlan litigation, however, had any particular motivation to dig deeper. Ms Quinlan's parents believed that she would have wished to die whether or not she was conscious, and the state believed that she should not be permitted to die whether or not she was conscious.

More telling still was the cross-examination of one of the medical witnesses. The question at issue was the difference between PVS, in which the patient is said to be irreversible and unconscious, and lockedin syndrome, where the patient can communicate.

'Q. From the locked-in syndrome theory -

A. It's not a "theory". It's a syndrome.

Q. Syndrome. That's where a person has some level of consciousness but can't do anything about it other than, perhaps, eye movement?

A. That's right. They can be completely aware conscious - aware and answer questions.

Q. Paralysed, other than their eyes. Is that correct?

A. That's right.

Q. Do you know of any situation where a person has had locked-in syndrome where even their eye function has not been normal? Or is it impossible to tell, because you don't know what's going on if you can't tell that the eyes work' (13)?

In response to what would seem an important practical question the doctor's answer loses coherence quickly, but his central imperatives are clear.

'A. ... There is such a situation that can occur, and it's theoretically possible, in terms of animal experiments. We've seen such patients with such things. There may be, who knows, mediation, but I don't know how you're going to find out. I think it's one of the most horrendous things you can imagine.

Q. You mean not knowing?

A. Well, no. Can you imagine that this individual is aware, at some level, and thinks' (13)?

We wish to believe that people in unendurable situations are unaware, and we resist evidence that would indicate otherwise. Some of us avert our eyes. 
Others elevate our disquiet to the status of a neurological theory and an ethical imperative.

The question is not one of the right to life, or the right to die. The ethical questions raised by PVS patients - questions of resource allocation, of substituted judgment, of quality of life - are not, or at least not entirely, dependent on whether or not they are or will become aware. One can rationally decide that care should be withdrawn from such people whether or not they will eventually demonstrate consciousness. One can rationally decide, for example, that if they are paralysed and comatose but in fact aware, then their situation is worse, not better, and their quittance more urgent. These questions do, however, surely depend crucially on the significance we attach to real and irremovable uncertainty.

Ethics yearns for the form of the syllogism of hard logic, the form 'All X are $\mathrm{Y}$; Karen is an X; therefore Karen is a $Y$ '. If this is rephrased as 'Some of $X$ are somewhere along the continuum of $\mathrm{Y}$, for an unpredictable period, to the extent that $\mathrm{X}$ and $\mathrm{Y}$ exist; Karen has been diagnosed, with an unknown degree of error, as X; we must guess at Karen's state in regard to $\mathrm{Y}$ as best we can on all the available evidence' then the importance of the ethicist is diminished to the extent that the bright clarity of theory is frittered away in the uncertainties of the quotidian experience.

If the discipline of ethics cannot cope with uncertainty, it is useless in the real world. If it persists in attempting to deny the existence of uncertainty, it may also be dangerous. Ethical rubrics may become a self-fulfilling prophecy - the prognosis is poor, therefore no treatment is given, therefore the prognosis is poor (and if, of course, patients with PVS are encouraged to die when ethicists believe that their condition is morally certain, then we can at least be sure that the number of disconfirming recoveries will drop to negligible proportions and the statistics will fall into line with the theories).

It surely matters immensely if people diagnosed as having PVS are not given pain relief when they may be in pain. It matters centrally to any notions of humanness if we allow ourselves to dismiss any class, $m$ and any person belonging to such a class, from the $\overrightarrow{\bar{\tau}}$. human race on a priori grounds rather than by ? examining their individual circumstances. I would $\Rightarrow$ suggest that while the arguments of ethicists can $\stackrel{\text { ? }}{+}$ perhaps provide thought-experiments, setting up? hypothetical cases where such treatment would be $\frac{\overline{\bar{c}}}{\overline{\mathrm{T}}}$. appropriate, these arguments are not adequate to $\frac{\widehat{\sigma}}{\bar{\phi}}$ establish the congruence of these hypothetical cases $\varrho$ with any situation in the real world.

Chris Borthwick, BA, LlB, is a Health Issues $\vec{\circ}$ Researcher at the Victorian Health Promotion $\vec{\omega}$ Foundation, Carlton, Australia. He is the author of Prevention of Disablement, Melbourne, Collins Dove, $\overrightarrow{\widetilde{\Phi}}$ 1994.

\section{References}

(1) Chambers D. Beasts and other illusions. Geelong: $\stackrel{ }{\supset}$ Deakin University, 1984: 3.

(2) McCullagh P. Brain dead, brain absent, and brain donors. Chichester: John Wiley, 1992: 128.

(3) Mitchell K, Kerridge I, Lovat T. Medical futility, $\stackrel{\oplus}{\oplus}$ treatment withdrawal, and the persistent vegetative $\vec{\bullet}$ state. Fournal of medical ethics 1993; 19: 71-76.

(4) See reference (3): 71.

(5) See reference (3): 72.

(6) Cefalo R, Englehart $H$. The use of fetal a然 anencephalic tissue for transplantation. fournal of medicine and philosophy 1989; 14: 25-43.

(7) See reference (2): 118.

(8) Levin H S, Saydjari C, Eisenberg H, et al. Vegetative state after closed head injury; a traumatic coma data bank report. Archives of neurology 1991; 48: 580-585.

(9) See reference (3): 73

(10) Singer $\mathbf{P}$. The future of Baby Doe. New York review of books 1984; 31, 3: 17-23.

(11) Robinson N, ed. In the matter of Karen Quinlan: The complete briefs, court proceedings and decision in the $\overline{0}$ Superior Court of New fersey. New York: University Publications of America, 1976: 545.

(12) See reference (11): V.II: xii.

(13) See reference (11): V.I: 332. 